\title{
Possible Ways to Improve Postprandial Glucose Control in Type 1 Diabetes
}

\author{
Halis Kaan Akturk, MD, Amanda Rewers, MD, Hal Joseph, PA, \\ Nicole Schneider, NP, and Satish K. Garg, MD
}

Keywords: Type 1 diabetes, Postprandial blood glucose, Insulin, Technosphere insulin, Postprandial glucose excursions, Fast-acting insulin, FIasp, BioChaperone insulin, STAT study, Hyperglycemia, Pramlintide, GLP-1 analog, Inhaled insulin.

\section{Introduction}

$\mathbf{T}$ he Diabetes Control and Complications Trial and subsequent Epidemiology of Diabetes Interventions and Complications trial have unequivocally established that intensive glucose control significantly reduces microvascular and macrovascular long-term diabetes complications in those with type 1 diabetes (T1D). ${ }^{1-3}$ The improvement in diabetes control was, however, associated with a threefold increase in severe hypoglycemia events, which in many cases result in additional calorie consumption, intentional hyperglycemia, limited insulin titration, and weight gain. ${ }^{4}$

Glucose control, as measured by $\mathrm{HbA}_{1 \mathrm{c}}$, is widely accepted as the hallmark measure of mean blood glucose (MBG), and is derived from a composite of fasting plasma glucose (FPG) and postprandial glucose (PPG) exposure. The exact role of postprandial hyperglycemia, and how it relates to glycated hemoglobin $\left(\mathrm{HbA}_{\mathrm{lc}}\right)$ are debatable. ${ }^{5-9}$ Some studies have shown a significant relationship of PPG with $\mathrm{HbA}_{1 \mathrm{c}}$ more than $\mathrm{FPG},{ }^{9,10}$ whereas other studies suggested the contrary. ${ }^{11,12}$ Postprandial hyperglycemia contributes significantly to overall glycemic burden and represents one of two key targets along with fasting glucose control for improvement in MBG.

One of the greatest challenges and unmet needs in diabetes management is limitations in effectively and consistently controlling postprandial hyperglycemia. ${ }^{3}$ Increased PPG levels have been significantly associated with increased healthcare resource utilization, including visits, calls, e-mails to healthcare providers, and overnight hospitalizations among adults with diabetes that use multiple daily injections (MDI). ${ }^{13} \mathrm{~A}$ measurement of plasma glucose (by self-monitored blood glucose-SMBG) $2 \mathrm{~h}$ after the start of a meal has commonly been recommended and has been a key indicator of postprandial hyperglycemia. ${ }^{14}$ At present, however, there is no international consensus for either the recommended measurement or specific targets for PPG levels for patients with diabetes. Current recommendations are neither well established nor consistently individualized for individuals with T1D; however, the recommended 2-h PPG level $<140 \mathrm{mg} / \mathrm{dL}$ has been suggested by the American Association of Clinical Endocrinologists (AACE); while values $<180 \mathrm{mg} / \mathrm{dL}$ have been put forth by the American Diabetes Association (ADA), targets of $<160-180 \mathrm{mg} / \mathrm{dL}$ were recommended by European Association for the Study of Diabetes (EASD), and $<160 \mathrm{mg} / \mathrm{dL}$ was the suggested target provided by International Diabetes Federation, all targeting these values with no increase in associated rates of significant hypoglycemia. ${ }^{13}$

\section{Importance of PPG Control}

A significant correlation has been observed between postprandial hyperglycemia and elevated intraocular pressure, ${ }^{15}$ cognitive dysfunction, ${ }^{16}$ oxidative stress, and many other conditions - with these data generally obtained in retrospective studies. ${ }^{17}$ The Framingham Offspring Study and the Diabetes Epidemiology: Collaborative analysis of Diagnostic criteria in Europe (DECODE) study showed a relationship between postprandial hyperglycemia and cardiovascular disease. ${ }^{18,19}$ The Study To Prevent NonInsulin-Dependent Diabetes Mellitus (STOP-NIDDM) trial has shown that decreasing postprandial hyperglycemia may reduce the incidence of new cardiovascular events in people with impaired glucose tolerance. ${ }^{20}$ However, the Hyperglycemia and Its Effect After Acute Myocardial Infarction on Cardiovascular Outcomes in Patients With Type 2 Diabetes Mellitus (HEART2D) study ${ }^{21}$ and the Nateglinide and Valsartan in Impaired Glucose Tolerance Outcomes Research (NAVIGATOR) study $^{22}$ failed to show beneficial effects of lowering PPG. ${ }^{23}$ A post hoc analysis of the data from the HEART2D study concluded a lower risk of

Barbara Davis Center for Diabetes - Adult Clinic, University of Colorado, Aurora, Colorado. 
cardiovascular events with prandial versus basal insulin therapy in a subgroup of older individuals with type 2 diabetes (T2D) and prior acute myocardial infarction, despite similar $\mathrm{HbA}_{1 \mathrm{c}}$ between the two groups. ${ }^{24}$ No well-controlled, randomized study to date has carefully assessed the impact of PPG excursions on rates of complications or outcomes in T1D.

In contrast, at this time, there is no definitive evidence for the precise relationship between PPG excursions and the development and progression of microvascular and macrovascular complications of diabetes. ${ }^{17,25}$ The ability to draw conclusions from long-term trials with head-to-head comparisons is difficult due to the absence of an ideal therapeutic agent that would only decrease PPG effectively and have a negligible effect on FPG. ${ }^{17}$ Difficulties in comparing trials to date are also due to limitations in study design, endpoints, and the methods of analysis employed. ${ }^{17}$

\section{Contributors to Postprandial Hyperglycemia}

The absorption of carbohydrates in the upper gastrointestinal (GI) tract results in increases in plasma glucose concentrations, which usually starts about 10-20 min after the start of a meal, but this effect can vary significantly based on a number of factors, including, meal composition, duration of diabetes, presence of autonomic dysfunction, and alterations in microbiota of the upper GI tract. ${ }^{26,27}$ In an individual without diabetes, plasma glucose peaks in $\sim 60$ min after the start of a typical meal and rarely exceeds $140 \mathrm{mg} / \mathrm{dL}$, usually returning to normal levels within 2 to $3 \mathrm{~h} .{ }^{14}$ The corresponding physiologic release of insulin coincides with meal ingestion and is stimulated by glucose (and free fatty acids) with both a rapid increase in insulin concentrations and onset of insulin action within the first 30-120 min after the meal. This response generally controls the significant increase in blood glucose in healthy individuals, regardless of the carbohydrate load consumed since patients with T1D have little or no residual beta cell function after 2 to 3 years following diagnosis (which is in contrast to T2D, where postprandial hyperglycemia is the consequence of both inadequate mealrelated insulin release and failure to suppress ongoing hepatic glucose production). However, in both scenarios, rapid prandial insulin effect that can mimic the time action profile of physiological insulin may be desirable in efforts to better control the meal-related excursions in glucose.

As noted previously, postprandial hyperglycemia in T1D is multifactorial, and in addition to the factors already discussed, individuals with T1D also have a postprandial paradoxical rise in glucagon (although lesser in magnitude to that seen in T2D), and PPG is impacted by timing, quantity, and composition of the meal, mismatch of meal absorption with exogenous insulin absorption and action (often maximal more than 1 to $2 \mathrm{~h}$ after injection), and patient-related causes such as reduced or skipped mealtime insulin dose or challenges with accuracy in estimating total carbohydrate intake. ${ }^{14,28-30}$

Carbohydrate counting has been shown to be an important determining factor of postprandial hypoglycemia and hyperglycemia. ${ }^{31}$ More recently, continuous glucose monitor (CGM) data revealed the PPG patterns in T1D, including rapid glucose spikes with high glycemic index carbohydrates and late postprandial hyperglycemia with increases in dietary fat and protein. ${ }^{32-36}$ High-fat meals may alter gastric emptying, often contributing to late blood glucose elevations that can occur as late as 4 to $5 \mathrm{~h}$ after the meal, ${ }^{32,33}$ and can increase free fatty acid levels that impair insulin sensitivity, and further contribute to higher glucose values. ${ }^{35}$ Higher protein intake has also been shown to increase PPG levels 3-5 h postmeal. ${ }^{32,37}$ A high-fat and high-protein meal consisting of similar amounts of carbohydrates require more insulin to lower PPG when compared with low-fat, low-protein meals in T1D. ${ }^{38}$

There are also data to suggest that food order has a significant role to play. A study showed that when protein and fat were consumed 15 min before carbohydrates, the mean PPG levels were lower by $28.6 \%, 36.7 \%$, and $16.8 \%$ at 30,60 , and $120 \mathrm{~min}$, respectively. ${ }^{39}$ The glycemic index of food may also affect PPG levels, as foods with a high glycemic index have been shown to result in even greater and more rapid increase in blood glucose following a meal. On the other hand, those foods with a lower glycemic index result in lesser fluctuations in blood glucose. ${ }^{40,41}$ One other key variable-namely the specific timing of the subcutaneous insulin dose-in relation to the meal has been shown to be an important factor in PPG control. ${ }^{32,33}$

A recent review concluded that injecting rapid-acting insulin analogs (RAIA; e.g., lispro, aspart, and glulisine) 1520 min premeal results in $\sim 30 \%$ lower PPG levels and lower reported rates of postmeal hypoglycemia when premeal glucose levels are in range. ${ }^{36}$ Postprandial administration of RAIAs is a less effective method of controlling PPG levels and may increase a significant risk of hypoglycemia and increased glucose variability. ${ }^{36}$

Therapeutic approaches for T1D management during exercise also need to account for the residual effects of meals, insulin dose, and the impact of activity on glucose turnover, insulin mobilization, glucagon, and sympathetic response. ${ }^{42}$ Several types of exercises are associated with rapid reductions in glucose (walking and jogging), while other forms of exercises may result in rapid increase in plasma glucose (weight training and high-intensity intervals). ${ }^{42}$ Duration and type of exercise must also be considered in preventing exercise-induced hypoglycemia and postexercise hyperglycemia. $^{43}$ The Dose Adjustment For Normal Eating (DAFNE) trial showed that dietary training with flexible insulin dosing improved diabetes outcomes and quality of life, and was costeffective. $^{44,45}$ The dietary changes recommended in the DAFNE trial persisted for 6 months and glycemic control was maintained up to 7 years. ${ }^{46,47}$

Gastroparesis is a relatively uncommon long-term complication in poorly controlled patients with diabetes. Patients with gastroparesis may have delayed glucose absorption, thus resulting in a delayed rise in PPG. ${ }^{48}$ Rarely, patients with gastroparesis may also have rapid absorption of food intake. The use of insulin pumps has been shown to improve PPG better than subjects using MDI. ${ }^{49}$

\section{Therapeutic Options to Address Prandial Glucose Control}

Many new basal insulin analogs such as insulin detemir, glargine (U100 and U300), and degludec (U100 and U200), or the use of insulin pumps has allowed effective control of FPG, most without increasing nocturnal hypoglycemia. ${ }^{50-54}$ In late March, the Food and Drug Administration (FDA) approved specific changes in wording for the use of insulin degludec based on results from the DEVOTE trial that reported reduced rates of severe hypoglycemia. ${ }^{55}$ 
Mealtime human soluble (regular) insulin (in contrast to porcine/bovine regular insulin) has been used since 1992 in an effort to control PPG. More recently, RAIAs (insulin lispro, glulisine, and aspart) have generally replaced human regular insulin in individuals with T1D as they are dosed closer to mealtime and have been shown to have a more rapid pharmacokinetic (PK) and pharmacodynamic (PD) response. ${ }^{56}$ The RAIAs have a more rapid onset of action, earlier and higher peak activity with a shorter duration of action than human regular insulin. ${ }^{56}$ However, RAIAs are still recommended for dosing 15-30 before meals and are known to have significant insulin effect more than $2 \mathrm{~h}$ after injection-which many consider inadequate to achieve optimal PPG control. ${ }^{56-58}$

Faster acting insulin aspart (FIasp) is a new formulation of insulin aspart that includes two additional formulation excipients, L-arginine and niacinamide. L-arginine serves as a stabilizing agent and the addition of niacinamide promotes a more rapid formation of insulin monomers after subcutaneous injection, facilitating more rapid absorption across the endothelium into the circulation. ${ }^{59}$ The pooled analysis of PK and PD studies that compared FIasp versus insulin aspart showed an $\sim 5$ min earlier onset of first appearance of insulin ( $4 \mathrm{vs} .9 \mathrm{~min}$ ), an approximately two times higher early insulin exposure, and a 74\% greater early glucose-lowering effect for Flasp versus insulin aspart. ${ }^{56}$ A Japanese study confirmed similar findings. ${ }^{60}$ Offset of exposure and glucose-lowering effect occurred 12 14 min earlier with FIasp than insulin aspart. ${ }^{56}$

The Onset 1 registration trial at 26 weeks showed not only noninferiority of FIasp in terms of $\mathrm{HbA}_{1 \mathrm{c}}$ compared to insulin aspart, but also superiority for PPG excursions $(21.21 \mathrm{mg} / \mathrm{dL}$ and $12.01 \mathrm{mg} / \mathrm{dL}$ decrease at 1 and $2 \mathrm{~h}$, respectively) without increased risk of hypoglycemia in patients with T1D. ${ }^{58}$ At 52 weeks in the same trial, overall glycemic control had significantly improved with FIasp versus insulin aspart, consistent with the 26-week study findings. ${ }^{57}$ A projection analysis that used the Onset 1 trial data showed that FIasp can reduce healthcare-related costs up to $£ 1,715$ in England. ${ }^{61}$ FIasp also improved glucose control in the registration Onsets 2 and 3 trials in patients with T2D. ${ }^{59,62}$ Currently, FIasp is not currently approved for use in insulin pumps used in the United States. In a recent 6-week small study for pump compatibility, no microscopically confirmed infusion-set occlusions were observed for FIasp. ${ }^{63}$

Glucagon-like peptide (GLP-1) is an incretin hormone secreted by intestinal L cells in response to food intake and works on suppressing postprandial glucagon release, increasing (on demand) insulin secretion (a mechanism not possible in patients with T1D due to general absence of betacell insulin release), increasing satiety, and delaying gastric emptying. ${ }^{30,64}$ Currently, none of the GLP-1 analogs is approved by the FDA to be used in T1D. Shorter-acting GLP-1 analogs have been shown to improve glucose control with associated reductions in insulin dose compared to placebo; however, long-acting GLP-1 analogs have shown to be less consistent as adjunctive therapy for glucose control in patients with T1D. ${ }^{65}$ In small studies, exenatide improved PPG in patients with T1D. ${ }^{66,67}$ Liraglutide did not demonstrate significantly greater effects on PPG control in patients with T1D. ${ }^{65,68}$ While improvement in $\mathrm{HbA}_{1 \mathrm{c}}$ was observed, the changes were small in magnitude_-although also associated with modest weight loss. Overall, the studies showed a significant increase in the risk of DKA and severe hypoglycemia in ADJUNCT 1 and 2 trials in T1D. ${ }^{69,70}$ As a result of these data, the developer of liraglutide officially announced that it would not pursue a new drug application (NDA) to the FDA or European Medicine Agency (EMA) for use of liraglutide for T1D as adjunctive therapy.

Pramlintide is an analog hormone to human amylin-a peptide synthesized in the pancreatic beta-cells and co-secreted with insulin. Pramlintide has been approved for adjunctive use in insulin-treated individuals with both T1D and T2D-and exerts its clinical effects by means of increases in satiety, a delay in gastric emptying, and reducing postprandial plasma glucagon concentrations. ${ }^{71}$ Premeal injections of pramlintide decreased glucose excursions for the first $2 \mathrm{~h}$ following a mixed meal by suppressing postprandial glucagon concentrations in a randomized crossover study. ${ }^{71}$ The time to peak blood glucose was also significantly slower with pramlintide. ${ }^{71}$ It has been shown that regardless of the duration of diabetes, patients achieved a significantly lower $\mathrm{HbA}_{1 \mathrm{c}}$ and weight loss; however, patients with increased duration of diabetes had significantly more adverse effects, including increased rates of nausea/vomiting and a higher risk of hypoglycemia. ${ }^{72}$ Another recent study compared pramlintide with liraglutide in patients with T1D in a closed-loop system without premeal bolus insulin administration. Pramlintide suppressed postmeal glucagon levels and lowered hyperglycemia. ${ }^{73}$ There is an ongoing study (NCT01269047) that compares exenatide and pramlintide in patients with T1D for PPG control. ${ }^{65}$

The only FDA-approved adjunctive therapy for T1D is pramlintide; however, its clinical use is limited due to a number of factors, including the need for significant adjustment in insulin dose in many individuals, treatment-limiting significant side effects such as nausea, vomiting, and decreased food intake in some individuals, and increased rates of hypoglycemia, as well as the higher cost of therapy. ${ }^{29}$ Pramlintide and GLP-1 analogs delay gastric emptying, and thus may help in delaying the absorption of glucose matching with the action of RAIA.

The SGLT2 inhibitors lower blood glucose through inhibition of renal glucose reabsorption in the proximal tubule of the kidney, whereas SGLT1 inhibition delays the absorption of glucose from the upper GI tract, thus blunting PPG. ${ }^{74,75}$ Sotagliflozin (dual SGLT1 and SGLT2 inhibitor) and dapagliflozin (selective SGLT2 inhibitor) have shown improved glucose control in patients with T1D in recently published randomized, controlled, double-blind studies. ${ }^{76-78}$ However, none of the SGLT (sodium-glucose cotransporter) inhibitors is FDA or EMA approved for clinical use in patients with T1D.

Inhaled insulin has been studied in several forms in an effort to utilize an alternate delivery method (pulmonary absorption) to alter PK/PD of mealtime insulin, while the earlier attempts at pulmonary insulin were generally unsuccessful due to low bioavailability $\left(\right.$ Exubera $^{\circledR}$ ) and limited improvement in time action profile, technology using fumaryl diketopiperazine (the excipient representing an essential part of Technosphere insulin [TI]) for pulmonary delivery of insulin (TI, Afrezza ${ }^{\circledR}$; Mannkind, Westlake Village, CA). TI had demonstrated even more rapid onset of action compared to the RAIA insulin lispro. ${ }^{79}$ TI appears in the blood in $<1 \mathrm{~min}$, thought to be due, in great part, to the extent of pulmonary alveolar space available for insulin absorption and due to the rapid dissolution of the insulin delivery particles. ${ }^{80} \mathrm{TI}$ also results in more rapid and higher 
peak action. ${ }^{81}$ In addition, a study of subjects with T2D has shown more rapid suppression of endogenous glucose production with $\mathrm{TI}$ at doses of 24 and $16 \mathrm{U}$ compared to lispro $10 \mathrm{U}^{82}$

Recently, data were provided to the U.S. FDA that resulted in changes in labeling language for TI that support the observation of the first measurable insulin effect that occurs in $\sim 12 \mathrm{~min}$, and peak effect is noted $\sim 35-45 \mathrm{~min}$ after dosing with a return to baseline insulin effect levels after $\sim 1.5-3 \mathrm{~h}^{83}$ Based on the PD, in these studies, the dose of TI required to achieve a similar glucose effect based on glucose infusion rate has been modified to at least 1.5 times the usual dose of subcutaneously injected RAIA. Whether this is the result of formulation properties, pulmonary delivery, or other changes in insulin action or clearance is not known. However, dosing (as an example) for a patient currently utilizing $8 \mathrm{U}$ of RAIA may require $12 \mathrm{U}$ of $\mathrm{TI}$ as an initial dose to achieve the similar glucose-lowering effect. ${ }^{84}$ This dosing recommendation is further supported by analysis of the doses of TI ultimately utilized to achieve similar glucose control in the randomized clinical trials comparing TI to RAIAs where equivalent dose ratios approximating 1.5-2 times dose of TI to RAIA were reported after 12 or more weeks of titration. ${ }^{85-87}$

TI was shown (by design) to achieve a noninferior reduction in $\mathrm{HbA}_{1 \mathrm{c}}$ when compared to RAIA in registration trials in those with T1D. This noninferiority was achieved with significantly less reported hypoglycemia and lesser weight gain compared to the use of RAIA. ${ }^{85}$ Additional studies confirmed reduced hypoglycemia - an outcome that is, in part, attributed to its rapid "on and off" insulin action with TI. ${ }^{85,88-90}$ The PD profile reported confers a faster onset and shorter duration of action that may permit more rapid postprandial insulin action that coincides with the rates of glucose absorption after meals. ${ }^{80}$ A simulation study using modeled data from TI clinical trials suggested that higher doses of TI premeal or split dosing premeal and postmeal of TI may provide improved PPG profile with lesser fluctuations in postmeal glucose than conventional treatment with subcutaneously administered rapid-acting insulin products, and would be likely to do so without increasing the risk of hypoglycemia. ${ }^{91}$

In current clinical use, there are higher rates of reported "underdosing" of TI as documented by lesser clinical effect when 1:1 mealtime insulin dose conversion is used. However, with additional clinical experience, patients and healthcare providers have been advised to consider the higher dose conversion when switching between RAIA and TI, and appropriate titration may allow for more aggressive and higher dosing of TI when clinically indicated. ${ }^{84}$ TI has a significantly shorter duration of action and different time action profile compared to RAIAs, and for many individuals may require a modified approach to both initiation and titration as well as supplemental dosing 1-3 h postmeal (by inhalation) to achieve the optimal clinical effect. Similarly, with shorter mealtime insulin action following TI inhalation, individual patients may also need to alter (generally increase) their basal insulin dose.

A small number of individual reports have identified those who have used TI for PPG control with the hybrid closed-loop (HCL) pump therapy. Given the short duration of action of inhaled TI with meals, and the flexibility of basal adjustments with HCL, some individuals report clinical improvement, although this is not currently an indicated use of TI. However, using TI with HCL system will not account for the total daily insulin dose and thus many patients may experience higher fasting glucose values, and usually not recommended.

A small $(n=15)$ pilot feasibility single-arm study using TI showed a decrease in $\mathrm{HbA}_{1 \mathrm{c}}$ in 6 weeks. ${ }^{92}$ An investigatorled collaborative open-label, multicenter randomized pilot study (Study Comparing Prandial Insulin Aspart vs. Technosphere Insulin in Patients with Type 1 Diabetes on MDI- or STAT Study) compared TI with insulin aspart effects on PPG control and postprandial time in range (TIR) for $0-4 \mathrm{~h}$ postmeal using CGM data. The STAT study showed that PPG was significantly lower at 1 and $2 \mathrm{~h}$ postprandial with TI compared to insulin aspart. ${ }^{89,90}$ In the per-protocol analysis (with additional postprandial TI dose), mean glucose values and postprandial TIR significantly improved compared to insulin aspart. ${ }^{89,90}$ Details of the STAT study results will be presented at the 2018 ADA and EASD annual meetings in Orlando, FL, and Berlin, Germany, respectively ${ }^{89,90}$ (data on file with BDC).

Due to the rising cost of insulin, biosimilar insulins are also now being developed as an alternative to the established branded RAIA. ${ }^{93-95}$ Similar PK/PD results have been demonstrated with biosimilar lispro versus insulin lispro in use. ${ }^{96}$ A crossover study that compared biosimilar lispro and insulin lispro in use for pump compatibility and safety found similar results for infusion set occlusions, hypersensitivity reactions, and hypoglycemia events. ${ }^{97}$ In T1D and T2D, similar efficacy and safety were found in the SORELLA 1 and SORELLA 2 studies, respectively. ${ }^{98,99}$ Similar immunogenicity profiles were found between biosimilar lispro and insulin lispro in use in the SORELLA 1 and SORELLA 2 studies. ${ }^{100}$ Earlier PK/PD studies with biosimilar (follow-on) insulin aspart also showed similar profiles to insulin aspart. Phase 3 clinical trials in T1D and T2D (GEMELLI studies) are ongoing in the United States and Europe for biosimilar insulin aspart approvals (NCT03211858) with the FDA and EMA. ${ }^{101}$

BioChaperone insulin lispro has also been developed to enable the acceleration of insulin absorption. It had previously demonstrated an accelerated insulin action profile across multiple phase 1 and 2 studies in people with T1D and T2D compared to insulin lispro. ${ }^{102-104}$ A trial (NCT03179332) that compared PK/PD properties of BioChaperone insulin lispro in insulin pumps with insulin aspart and FIasp recently showed superior results according to a press release by Adocia, Inc. (Lyon, France). ${ }^{105}$ Eli Lilly \& Co, Inc. (Indianapolis, IN) recently completed the recruitment for the phases 2 to 3 trials for ultra-rapid-acting insulin lispro for MDI and continuous subcutaneous insulin infusion (CSII) (NCT03056456 and NCT02703350). ${ }^{104}$ Results from early phase studies of this compound supported faster time action profile than insulin lispro, although full results of phase 3 studies are not currently available. ${ }^{106,107}$

Some other alternative methods have been tried to increase insulin absorption. Insulin co-injected with hyaluronidase to increase insulin absorption may be a promising alternative for PPG management. ${ }^{108-110}$ Despite favorable results, the company (Halozyme, Inc., San Diego, CA) discontinued development of their product, given both the clinical and regulatory requirements necessary to complete the NDA for the FDA. Investigational devices that apply local heat have been found to increase insulin absorption and thus reduce PPG. ${ }^{111-114}$ Whether such approaches will achieve improved PPG remains to be determined. 


\section{Conclusion}

The recent availability of HCL systems (artificial pancreas or AP systems) to deliver insulin in response to CGM recorded glucose data and specific insulin administration algorithms have been reported, and demonstrate significant reductions in fasting glucose in many trials. ${ }^{52,54}$ However, control of PPG continues to remain a clinical challenge as it requires patient input of proper carbohydrate intake and current insulin action profiles may be limited to respond to rapid increases and decreases in PPG even with the HCL system. CSII or pumps are currently only used in $<1 \%$ of insulin-requiring patients, so the generalizability of such therapy remains to be determined.

Identification of optimal basal and prandial insulin therapies that better mimic normal physiology and utilize rapid and frequent glucose measurement that can facilitate/help patients manage their diabetes at the moment is needed for more effective management. There also remain ongoing efforts to identify a "SMART" (glucose sensing) insulin that alleviates the need for multiple insulin types and may eliminate the need for advanced pump technologies. One such approach uses boronate-based glucose sensing (that is attached to the insulin molecules) for continuous sensing. ${ }^{115,116}$

Effective PPG control still requires multiple daily efforts that include, but are not limited to the following: proper and accurate assessment of carbohydrate intake (DAFNE trial), food composition, insulin dose adjustments based on physical activity, current glucose level (as measured by SMBG), or real-time CGM. ${ }^{30}$ CGM data allow patients and healthcare providers real-time feedback to control PPG more effectively. ${ }^{117-119}$ Patients using insulin pumps may bolus with different options (standard, square wave, modified combination, and dual wave) to improve PPG control, especially in patients with gastroparesis. ${ }^{120-122}$ Development of ultra-RAIA and proper use of very rapid-acting pulmonary insulin such as TI can assist a number of patients in their effort to improve PPG. Until another very rapid-acting prandial insulin is available, appropriate use of currently available insulins (aspart, lispro, glulisine, FIasp, and Technosphere Insulin) along with glucose monitoring (SMBG/CGM) should be considered the standard of care to mitigate/reduce PPG elevations and excursions.

\section{Author Disclosure Statement}

S.K.G. has received Advisory Board Consulting fees from Medtronic, Roche, Merck, Lexicon, Novo-Nordisk, Sanofi, Mannkind, Senseonics, Zealand, and Eli Lilly. S.K.G. has received research grants through the University of Colorado Denver from Eli Lilly, Novo-Nordisk, Merck, Lexicon, Medtronic, Dario, NCI, T1D Exchange, NIDDK, JDRF, Animas, Dexcom, and Sanofi. S.K.G. does not own stocks in any device or pharmaceutical company. H.K.A. has received research grant through the University of Colorado Denver from Mannkind Corporation. Other authors do not have any conflict of interests.

\section{References}

1. Orchard TJ, Nathan DM, Zinman B, et al.: Association between 7 years of intensive treatment of type 1 diabetes and long-term mortality. JAMA 2015;313:45-53.

2. de Boer IH, Rue TC, Cleary PA, et al.: Long-term renal outcomes of patients with type 1 diabetes mellitus and microalbuminuria: an analysis of the Diabetes Control and Complications Trial/Epidemiology of Diabetes Interventions and Complications cohort. Arch Intern Med 2011; 171:412-420.

3. Nathan DM, Cleary PA, Backlund JY, et al.: Intensive diabetes treatment and cardiovascular disease in patients with type 1 diabetes. N Engl J Med 2005;353:2643-2653.

4. Miller KM, Foster NC, Beck RW, et al.: Current state of type 1 diabetes treatment in the U.S.: updated data from the T1D exchange clinic registry. Diabetes Care 2015;38: 971-978.

5. Landgraf R: The relationship of postprandial glucose to HbA1c. Diabetes Metab Res Rev 2004;20(Suppl 2): S9-S12.

6. Bonora E, Tuomilehto J: The pros and cons of diagnosing diabetes with A1C. Diabetes Care 2011;34(Suppl 2): S184-S190.

7. Monnier L, Lapinski H, Colette C: Contributions of fasting and postprandial plasma glucose increments to the overall diurnal hyperglycemia of type 2 diabetic patients: variations with increasing levels of $\mathrm{HbA}(1 \mathrm{c})$. Diabetes Care 2003;26:881-885.

8. Monnier L, Colette C: Postprandial and basal hyperglycaemia in type 2 diabetes: contributions to overall glucose exposure and diabetic complications. Diabetes Metab 2015;41(Suppl 1):6S9-6S15.

9. Ketema EB, Kibret KT: Correlation of fasting and postprandial plasma glucose with HbA1c in assessing glycemic control; systematic review and meta-analysis. Arch Public Health 2015;73:43.

10. Haddadinezhad S, Ghazaleh N: Relation of fasting and postprandial and plasma glucose with hemoglobin A1c in diabetics. Int J Diabetes Dev Ctries 2010;30:8-10.

11. Hillman N, Herranz L, Grande C, et al.: Is $\mathrm{HbA}(1 \mathrm{c})$ influenced more strongly by preprandial or postprandial glycemia in type 1 diabetes? Diabetes Care 2002;25: 1100-1101.

12. Gupta S, Puppalwar P, Chalak A: Correlation of fasting and post meal plasma glucose level to increased HbAlc levels in type-2 diabetes mellitus. Int J Adv Med 2014;1: 127-131.

13. Pfeiffer KM, Sandberg A, Nikolajsen A, Brod M: Postprandial glucose and healthcare resource use: a crosssectional survey of adults with diabetes treated with basalbolus insulin. J Med Econ 2018;21:66-73.

14. American Diabetes Association: Postprandial blood glucose. Diabetes Care 2001;24:775-778.

15. Wu CJ, Fang WH, Kao TW, et al.: Postprandial glucose as a risk factor for elevated intraocular pressure. PLoS One 2016;11:e0168142.

16. Abbatecola AM, Rizzo MR, Barbieri M, et al.: Postprandial plasma glucose excursions and cognitive functioning in aged type 2 diabetics. Neurology 2006;67: 235-240.

17. Madsbad S: Impact of postprandial glucose control on diabetes-related complications: how is the evidence evolving? J Diabetes Complications 2016;30:374-385.

18. DECODE Study Group: Glucose tolerance and cardiovascular mortality: comparison of fasting and 2-hour diagnostic criteria. Arch Intern Med 2001;161:397-405.

19. Meigs JB, Nathan DM, D'Agostino RB, Sr., Wilson PW: Fasting and postchallenge glycemia and cardiovascular disease risk: the Framingham Offspring Study. Diabetes Care 2002;25:1845-1850. 
20. Chiasson JL, Josse RG, Gomis R, et al.: Acarbose treatment and the risk of cardiovascular disease and hypertension in patients with impaired glucose tolerance: the STOP-NIDDM trial. JAMA 2003;290:486-494.

21. Raz I, Wilson PW, Strojek K, et al.: Effects of prandial versus fasting glycemia on cardiovascular outcomes in type 2 diabetes: the HEART2D trial. Diabetes Care 2009; 32:381-386.

22. Holman RR, Haffner SM, McMurray JJ, et al.: Effect of nateglinide on the incidence of diabetes and cardiovascular events. N Engl J Med 2010;362:1463-1476.

23. Ceriello A: Point: postprandial glucose levels are a clinically important treatment target. Diabetes Care 2010;33: 1905-1907.

24. Raz I, Ceriello A, Wilson PW, et al.: Post hoc subgroup analysis of the HEART2D trial demonstrates lower cardiovascular risk in older patients targeting postprandial versus fasting/premeal glycemia. Diabetes Care 2011;34: 1511-1513.

25. IDF: Guideline for Management of Postmeal Glucose. https:// webcache.googleusercontent.com/search?q=cache:esd0 MMBiEdMJ:https://www.idf.org/component/attachments/ attachments.html\%3Fid\%3D728\%26task\%3Ddownload+ $\& \mathrm{~cd}=1 \& \mathrm{hl}=\mathrm{en} \& \mathrm{ct}=\mathrm{clnk} \& \mathrm{gl}=\mathrm{us}$. Accessed May 15, 2018.

26. Utzschneider KM, Kratz M, Damman CJ, Hullarg M: Mechanisms linking the gut microbiome and glucose metabolism. J Clin Endocrinol Metab 2016;101:1445-1454.

27. Dietary Advice Based on the Bacteria in Your Gut. www .wsj.com/articles/dietary-advice-based-on-the-bacteria-inyour-gut-1519614301 mod=searchresults\&page=1\&pos= 11 (accessed March 27, 2018).

28. Cobry E, McFann K, Messer L, et al.: Timing of meal insulin boluses to achieve optimal postprandial glycemic control in patients with type 1 diabetes. Diabetes Technol Ther 2010;12:173-177.

29. Frandsen CS, Dejgaard TF, Madsbad S: Non-insulin drugs to treat hyperglycaemia in type 1 diabetes mellitus. Lancet Diabetes Endocrinol 2016;4:766-780.

30. Gingras V, Taleb N, Roy-Fleming A, et al.: The challenges of achieving postprandial glucose control using closedloop systems in patients with type 1 diabetes. Diabetes Obes Metab 2018;20:245-256.

31. Deeb A, Al Hajeri A, Alhmoudi I, Nagelkerke N: Accurate carbohydrate counting is an important determinant of postprandial glycemia in children and adolescents with type 1 diabetes on insulin pump therapy. J Diabetes Sci Technol 2017;11:753-758.

32. Bell KJ, Smart CE, Steil GM, et al.: Impact of fat, protein, and glycemic index on postprandial glucose control in type 1 diabetes: implications for intensive diabetes management in the continuous glucose monitoring era. Diabetes Care 2015;38:1008-1015.

33. Wolpert HA, Atakov-Castillo A, Smith SA, Steil GM: Dietary fat acutely increases glucose concentrations and insulin requirements in patients with type 1 diabetes: implications for carbohydrate-based bolus dose calculation and intensive diabetes management. Diabetes Care 2013;36:810-816.

34. Smart CE, Evans M, O'Connell SM, et al.: Both dietary protein and fat increase postprandial glucose excursions in children with type 1 diabetes, and the effect is additive. Diabetes Care 2013;36:3897-3902.

35. James ML, Green L, Amiel SA, Choudhary P: Evaluation of the effect of carbohydrate intake on postprandial glucose in patients with type 1 diabetes treated with insulin pumps. J Diabetes Sci Technol 2016;10:1287-1293.

36. Slattery D, Amiel SA, Choudhary P: Optimal prandial timing of bolus insulin in diabetes management: a review. Diabet Med 2018;35:306-316.

37. Paterson MA, Smart CE, Lopez PE, et al.: Influence of dietary protein on postprandial blood glucose levels in individuals with type 1 diabetes mellitus using intensive insulin therapy. Diabet Med 2016;33:592-598.

38. Bell KJ, Toschi E, Steil GM, Wolpert HA: Optimized mealtime insulin dosing for fat and protein in type 1 diabetes: application of a model-based approach to derive insulin doses for open-loop diabetes management. Diabetes Care 2016;39: 1631-1634.

39. Shukla AP, Iliescu RG, Thomas CE, Aronne LJ: Food order has a significant impact on postprandial glucose and insulin levels. Diabetes Care 2015;38:e98-e99.

40. Lafrance L, Rabasa-Lhoret R, Poisson D, et al.: Effects of different glycaemic index foods and dietary fibre intake on glycaemic control in type 1 diabetic patients on intensive insulin therapy. Diabet Med 1998;15:972-978.

41. Hashimoto S, Noguchi CC, Furutani E: Postprandial blood glucose control in type 1 diabetes for carbohydrates with varying glycemic index foods. Conf Proc IEEE Eng Med Biol Soc 2014;2014:4835-4838.

42. Mallad A, Hinshaw L, Schiavon M, et al.: Exercise effects on postprandial glucose metabolism in type 1 diabetes: a triple-tracer approach. Am J Physiol Endocrinol Metab 2015;308:E1106-E1115.

43. Riddell MC, Gallen IW, Smart CE, et al.: Exercise management in type 1 diabetes: a consensus statement. Lancet Diabetes Endocrinol 2017;5:377-390.

44. Training in flexible, intensive insulin management to enable dietary freedom in people with type 1 diabetes: Dose Adjustment for Normal Eating (DAFNE) randomised controlled trial. BMJ 2002;325:746.

45. Kruger J, Brennan A, Thokala P, et al.: The costeffectiveness of the Dose Adjustment for Normal Eating (DAFNE) structured education programme: an update using the Sheffield Type 1 Diabetes Policy Model. Diabet Med 2013;30:1236-1244.

46. Casey D, Murphy K, Lawton J, et al.: A longitudinal qualitative study examining the factors impacting on the ability of persons with T1DM to assimilate the Dose Adjustment for Normal Eating (DAFNE) principles into daily living and how these factors change over time. BMC Public Health 2011;11:672.

47. Gunn D, Mansell P: Glycaemic control and weight 7 years after Dose Adjustment For Normal Eating (DAFNE) structured education in type 1 diabetes. Diabet Med 2012; 29:807-812.

48. Olausson EA, Grundin H, Isaksson M, et al.: Postprandial plasma glucose response and gastrointestinal symptom severity in patients with diabetic gastroparesis. J Diabetes Sci Technol 2014;8:881-888.

49. Sharma D, Morrison G, Joseph F, et al.: The role of continuous subcutaneous insulin infusion therapy in patients with diabetic gastroparesis. Diabetologia 2011;54: 2768-2770.

50. Marso SP, McGuire DK, Zinman B, et al.: Efficacy and safety of degludec versus glargine in type 2 diabetes. $\mathrm{N}$ Engl J Med 2017;377:723-732.

51. Lane W, Bailey TS, Gerety G, et al.: Effect of Insulin Degludec vs Insulin Glargine U100 on hypoglycemia in 
patients with type 1 diabetes: the SWITCH 1 randomized clinical trial. JAMA 2017;318:33-44.

52. Garg SK, Weinzimer SA, Tamborlane WV, et al.: Glucose outcomes with the in-home use of a hybrid closed-loop insulin delivery system in adolescents and adults with type 1 diabetes. Diabetes Technol Ther 2017;19:155-163.

53. Riddle MC, Bolli GB, Ziemen $\mathrm{M}$, et al.: New insulin glargine 300 units $/ \mathrm{mL}$ versus glargine 100 units $/ \mathrm{mL}$ in people with type 2 diabetes using basal and mealtime insulin: glucose control and hypoglycemia in a 6-month randomized controlled trial (EDITION 1). Diabetes Care 2014;37:2755-2762.

54. Bergenstal RM, Garg S, Weinzimer SA, et al.: Safety of a hybrid closed-loop insulin delivery system in patients with type 1 diabetes. JAMA 2016;316:1407-1408.

55. FDA approves inclusion of data from safety outcomes trial in the Tresiba ${ }^{\circledR}$ label. http://press.novonordisk-us.com/ 2018-03-26-FDA-approves-inclusion-of-data-from-safetyoutcomes-trial-in-the-Tresiba-R-label (accessed March 27, 2018).

56. Heise T, Pieber TR, Danne T, et al.: A pooled analysis of clinical pharmacology trials investigating the pharmacokinetic and pharmacodynamic characteristics of fast-acting insulin aspart in adults with type 1 diabetes. Clin Pharmacokinet 2017;56:551-559.

57. Mathieu C, Bode BW, Franek E, et al.: Efficacy and safety of fast-acting insulin aspart in comparison with insulin aspart in type 1 diabetes (onset 1): a 52-week, randomized, treat-to-target, phase III trial. Diabetes Obes Metab 2018;20:1148-1155.

58. Russell-Jones D, Bode BW, De Block C, et al.: Fast-acting insulin aspart improves glycemic control in basal-bolus treatment for type 1 diabetes: results of a 26-week multicenter, active-controlled, treat-to-target, randomized, parallelgroup trial (onset 1). Diabetes Care 2017;40:943-950.

59. Bowering K, Case C, Harvey J, et al.: Faster aspart versus insulin aspart as part of a basal-bolus regimen in inadequately controlled type 2 diabetes: the onset 2 trial. Diabetes Care 2017;40:951-957.

60. Shiramoto M, Nishida T, Hansen AK, Haahr H: Fast-acting insulin aspart in Japanese patients with type 1 diabetes: faster onset, higher early exposure and greater early glucoselowering effect relative to insulin aspart. J Diabetes Investig 2018;9:303-310.

61. Russell-Jones D, Heller SR, Buchs S, et al.: Projected long-term outcomes in patients with type 1 diabetes treated with fast-acting insulin aspart vs conventional insulin aspart in the UK setting. Diabetes Obes Metab 2017; 19:1773-1780.

62. Rodbard HW, Tripathy D, Vidrio Velazquez M, et al.: Adding fast-acting insulin aspart to basal insulin significantly improved glycaemic control in patients with type 2 diabetes: a randomized, 18-week, open-label, phase 3 trial (onset 3). Diabetes Obes Metab 2017;19:1389-1396.

63. Zijlstra E, Demissie M, Graungaard T, et al.: Investigation of pump compatibility of fast-acting insulin aspart in subjects with type 1 diabetes. J Diabetes Sci Technol 2018; 12:145-151.

64. Prasad-Reddy L, Isaacs D: A clinical review of GLP-1 receptor agonists: efficacy and safety in diabetes and beyond. Drugs Context 2015;4:212283.

65. Alber A, Bronden A, Knop FK: Short-acting glucagon-like peptide-1 receptor agonists as add-on to insulin therapy in type 1 diabetes: a review. Diabetes Obes Metab 2017;19: 915-925.

66. Raman VS, Mason KJ, Rodriguez LM, et al.: The role of adjunctive exenatide therapy in pediatric type 1 diabetes. Diabetes Care 2010;33:1294-1296.

67. Ghazi T, Rink L, Sherr JL, Herold KC: Acute metabolic effects of exenatide in patients with type 1 diabetes with and without residual insulin to oral and intravenous glucose challenges. Diabetes Care 2014;37:210-216.

68. Pieber TR, Deller S, Korsatko S, et al.: Counter-regulatory hormone responses to hypoglycaemia in people with type 1 diabetes after 4 weeks of treatment with liraglutide adjunct to insulin: a randomized, placebo-controlled, double-blind, crossover trial. Diabetes Obes Metab 2015;17:742-750.

69. Ahren B, Hirsch IB, Pieber TR, et al.: Efficacy and safety of liraglutide added to capped insulin treatment in subjects with type 1 diabetes: the ADJUNCT TWO randomized trial. Diabetes Care 2016;39:1693-1701.

70. Mathieu C, Zinman B, Hemmingsson JU, et al.: Efficacy and safety of liraglutide added to insulin treatment in type 1 diabetes: the ADJUNCT ONE treat-to-target randomized trial. Diabetes Care 2016;39:1702-1710.

71. Hinshaw L, Schiavon M, Dadlani V, et al.: Effect of pramlintide on postprandial glucose fluxes in type 1 diabetes. J Clin Endocrinol Metab 2016;101:1954-1962.

72. Herrmann K, Brunell SC, Li Y, et al.: Impact of disease duration on the effects of pramlintide in type 1 diabetes: a post hoc analysis of three clinical trials. Adv Ther 2016; 33:848-861.

73. Galderisi A, Sherr J, VanName M, et al.: Pramlintide but not liraglutide suppresses meal-stimulated glucagon responses in type 1 diabetes. J Clin Endocrinol Metab 2018; 103:1088-1094.

74. Oktay AA, Akturk HK, Jahangir E: Diabetes mellitus and hypertension: a dual threat. Curr Opin Cardiol 2016;31: 402-409.

75. Dobbins RL, Greenway FL, Chen L, et al.: Selective sodium-dependent glucose transporter 1 inhibitors block glucose absorption and impair glucose-dependent insulinotropic peptide release. Am J Physiol Gastrointest Liver Physiol 2015;308:G946-G954.

76. Sands AT, Zambrowicz BP, Rosenstock J, et al.: Sotagliflozin, a dual SGLT1 and SGLT2 inhibitor, as adjunct therapy to insulin in type 1 diabetes. Diabetes Care 2015; 38:1181-1188.

77. Garg SK, Strumph P: Effects of sotagliflozin added to insulin in type 1 diabetes. N Engl J Med 2018;378: 967-968.

78. Dandona P, Mathieu C, Phillip M, et al.: Efficacy and safety of dapagliflozin in patients with inadequately controlled type 1 diabetes (DEPICT-1): 24 week results from a multicentre, double-blind, phase 3, randomised controlled trial. Lancet Diabetes Endocrinol 2017;5: 864-876.

79. Nuffer W, Trujillo JM, Ellis SL: Technosphere Insulin (Afrezza): a new, inhaled prandial insulin. Ann Pharmacother 2015;49:99-106.

80. Heinemann L, Baughman R, Boss A, Hompesch M: Pharmacokinetic and pharmacodynamic properties of a novel inhaled insulin. J Diabetes Sci Technol 2017;11:148-156.

81. Goldberg T, Wong E: Afrezza (insulin human) inhalation powder: a new inhaled insulin for the management of type-1 or type-2 diabetes mellitus. P T 2015;40:735-741. 
82. Potocka E: Characterization of metabolism parameters following Technosphere[reg] Insulin and insulin lispro. American Diabetes Association, 2010. Abstract number: 1561-P. Characterization of Metabolism Parameters Following Technosphere[reg] Insulin and Insulin Lispro.

83. Afrezza label information. www.afrezza.com/new_pi_article (accessed March 16, 2018).

84. Pettus J, Cavaiola TS, Edelman SV: Recommendations for initiating use of Afrezza inhaled insulin in individuals with type 1 diabetes. Diabetes Technol Ther 2018;20:000-000.

85. Bode BW, McGill JB, Lorber DL, et al.: Inhaled technosphere insulin compared with injected prandial insulin in type 1 diabetes: a randomized 24-week trial. Diabetes Care 2015;38:2266-2273.

86. Rosenstock J, Franco D, Korpachev V, et al.: Inhaled technosphere insulin versus inhaled technosphere placebo in insulin-naive subjects with type 2 diabetes inadequately controlled on oral antidiabetes agents. Diabetes Care 2015;38:2274-2281.

87. Rosenstock J, Lorber DL, Gnudi L, et al.: Prandial inhaled insulin plus basal insulin glargine versus twice daily biaspart insulin for type 2 diabetes: a multicentre randomised trial. Lancet 2010;375:2244-2253.

88. Pittas AG, Westcott GP, Balk EM: Efficacy, safety, and patient acceptability of technosphere inhaled insulin for people with diabetes: a systematic review and meta-analysis. Lancet Diabetes Endocrinol 2015;3:886-894.

89. Akturk H, Snell-Bergeon J, Rewers A, et al.: Improved Post-prandial Blood Glucose Excursions with Technosphere Inhaled Insulin Compared to Aspart in T1D Patients-STAT Study. Orlando, FL: American Diabetes Association, 2018.

90. Akturk H, Snell-Bergeon J, Rewers A, et al.: Improved Time-in-Range on Continuous Glucose Monitor with Technosphere Inhaled Insulin Compared to Insulin Aspart in T1D Patients-STAT Study. Orlando, FL: American Diabetes Association, 2018.

91. Visentin R, Giegerich C, Jager R, et al.: Improving efficacy of inhaled Technosphere Insulin (Afrezza) by postmeal dosing: in-silico clinical trial with the University of Virginia/Padova Type 1 Diabetes Simulator. Diabetes Technol Ther 2016;18:574-585.

92. Garg SK, Kelly W, Freson B, Ritchie P: Treat-to-target Technosphere[reg] Insulin in patients with type 1 diabetes. American Diabetes Association. Abstract number: 941P. https://professional.diabetes.org/abstract/treat-targettechnospherereg-insulin-patients-type-1-diabetes. Accessed May 15, 2018.

93. Danne T, Heinemann L, Bolinder J: New insulins, biosimilars, and insulin therapy. Diabetes Technol Ther 2017;19(Suppl 1): S42-S58.

94. Heinemann L, Hompesch M: Biosimilar insulins: basic considerations. J Diabetes Sci Technol 2014;8:6-13.

95. Edelman S, Polonsky WH, Parkin CG: Biosimilar insulins are coming: what they are, what you need to know. Curr Med Res Opin 2014;30:2217-2222.

96. Kapitza C, Nowotny I, Lehmann A, et al.: Similar pharmacokinetics and pharmacodynamics of rapid-acting insulin lispro products SAR342434 and US- and EU-approved Humalog in subjects with type 1 diabetes. Diabetes Obes Metab 2017;19:622-627.

97. Thrasher J, Surks H, Nowotny I, et al.: Safety of insulin lispro and a biosimilar insulin lispro when administered through an insulin pump. J Diabetes Sci Technol 2018;12: 680-686.
98. Garg SK, Wernicke-Panten K, Rojeski M, et al.: Efficacy and safety of biosimilar SAR342434 insulin lispro in adults with type 1 diabetes also using insulin glargine-SORELLA 1 study. Diabetes Technol Ther 2017;19:516-526.

99. Derwahl KM, Bailey TS, Wernicke-Panten K, et al.: Efficacy and safety of biosimilar SAR342434 insulin lispro in adults with type 2 diabetes, also using insulin glargine: SORELLA 2 study. Diabetes Technol Ther 2018;20:49-58.

100. Home P, Derwahl KM, Ziemen M, et al.: Anti-insulin antibodies and adverse events with biosimilar insulin lispro compared with humalog insulin lispro in people with diabetes. Diabetes Technol Ther 2018;20:160-170.

101. Insulin aspart rapid-acting-Sanofi. https://adisinsight. springer.com/drugs/800048894 (accessed March 26, 2018).

102. Ultra-rapid BioChaperone Lispro improves post-prandial blood glucose excursions versus insulin lispro in a 14-day treatment study in subjects with type 1 diabetes. www .adocia.com/wp-content/uploads/2017/09/170905-EASDCurtain-Raiser-EN.pdf (accessed March 16, 2018).

103. Andersen G, Meiffren G, Alluis B, et al. Ultra-Rapid BioChaperoneLispro Ameliorates Postprandial Blood Glucose (PPG) Control Compared with Humalog in Subjects with Type 1 Diabetes Mellitus (NCT02528396). ADA 76th Scientific Sessions, New Orleans, LA, 2016.

104. Danne T, Heinemann L, Bolinder J: New insulins, biosimilars, and insulin therapy. Diabetes Technol Ther 2018; 20(Suppl 1):S55-S70.

105. Study results comparing ultra-rapid insulin BioChaperone ${ }^{\circledR}$ Lispro with Novolog ${ }^{\circledR}$ and Fiasp ${ }^{\circledR}$ in people with type 1 diabetes. www.adocia.com/wp-content/uploads/2017/12/17 1206-BC-Lispro-Fiasp-Study-Results-ENG.pdf (accessed March 16, 2018).

106. Kazda C, Leohr J, Liu R, et al.: A Novel Formulation of Insulin Lispro Containing Citrate and Treprostinil Shows Faster Absorption and Improved Postprandial Glucose Excursions vs. Humalog in Patients with T1DM. American Diabetes Association. Abstract number: 959-P, 2017.

107. Michael MD Zhang C, Siesky AM, et al.: Exploration of the mechanism of accelerated absorption for a novel insulin lispro formulation. American Diabetes Association. Abstract number: 968-P, 2017.

108. Garg SK, Buse JB, Skyler JS, et al.: Subcutaneous injection of hyaluronidase with recombinant human insulin compared with insulin lispro in type 1 diabetes. Diabetes Obes Metab 2014;16:1065-1069.

109. Morrow L, Muchmore DB, Hompesch M, et al.: Comparative pharmacokinetics and insulin action for three rapid-acting insulin analogs injected subcutaneously with and without hyaluronidase. Diabetes Care 2013;36: 273-275.

110. Hompesch M, Muchmore DB, Morrow L, Vaughn DE: Accelerated insulin pharmacokinetics and improved postprandial glycemic control in patients with type 1 diabetes after coadministration of prandial insulins with hyaluronidase. Diabetes Care 2011;34:666-668.

111. Freckmann G, Pleus S, Westhoff A, et al.: Clinical performance of a device that applies local heat to the insulin infusion site: a crossover study. J Diabetes Sci Technol 2012;6:320-327.

112. Freckmann G, Pleus S, Haug C, et al.: Increasing local blood flow by warming the application site: beneficial effects on postprandial glycemic excursions. J Diabetes Sci Technol 2012;6:780-785. 
113. Hermanns N, Bitton G, Reimer A, et al.: Effect of local heating on postprandial blood glucose excursions using the InsuPad device: results of an outpatient crossover study. J Diabetes Sci Technol 2014;8:1126-1132.

114. Landau Z, Klonoff D, Nayberg I, et al.: Improved pharmacokinetic and pharmacodynamic profiles of insulin analogues using InsuPatch, a local heating device. Diabetes Metab Res Rev 2014;30:686-692.

115. Dasgupta I, Tanifum EA, Srivastava M, et al.: Non inflammatory boronate based glucose-responsive insulin delivery systems. PLoS One 2012;7:e29585.

116. Chou DH, Webber MJ, Tang BC, et al.: Glucoseresponsive insulin activity by covalent modification with aliphatic phenylboronic acid conjugates. Proc Natl Acad Sci U S A 2015;112:2401-2406.

117. Freeman J, Lyons L: The use of continuous glucose monitoring to evaluate the glycemic response to food. Diabetes Spectrum 2008;21:134-137.

118. Pettus J, Edelman SV: Recommendations for using realtime continuous glucose monitoring (rtCGM) data for insulin adjustments in type 1 diabetes. J Diabetes Sci Technol 2017;11:138-147.

119. Klonoff DC, Kerr D: A simplified approach using rate of change arrows to adjust insulin with real-time continuous glucose monitoring. J Diabetes Sci Technol 2017;11: 1063-1069.

120. King $\mathrm{AB}$ : Comparison of the post-meal glucose response to different insulin bolus waveforms in insulin pump- and pre-meal pramlintide-treated type 1 diabetes patients. Diabetes Technol Ther 2010;12:105-108.

121. Chase HP, Saib SZ, MacKenzie T, et al.: Post-prandial glucose excursions following four methods of bolus insulin administration in subjects with type 1 diabetes. Diabet Med 2002;19:317-321.

122. Aleppo G, Calhoun P, Foster NC, et al.: Reported gastroparesis in adults with type 1 diabetes (T1D) from the T1D exchange clinic registry. J Diabetes Complications 2017;31:1669-1673.

Address correspondence to: Halis Kaan Akturk, MD

Barbara Davis Center for Diabetes - Adult Clinic University of Colorado

1775 Aurora Court, A140 Aurora, CO 80045

E-mail: halis.akturk@ucdenver.edu 